DOI: 10.12731/2077-1770-2020-6-197-210

УДК 811.111

\title{
ФРАЗЕОЛОГИЧЕСКИЕ ГЛАГОЛЫ \\ КАК СРЕДСТВА ПОВЫШЕНИЯ ЭКСПРЕССИВНОСТИ ДИСКУРСА МАССМЕДИА
}

\section{Радюк А.В., Храмченко Д.С.}

Цель. Работа посвящена исследованию функиионирования фразеологических глаголов как одного из речевых средств, составляющих систему речевого выражения коммуникативного замысла автора публицистической статьи. Целью статьи является анализ речевых средств, применяемых в англоязычной качественной прессе, для формирования оченочной окраски событий, формирования определенного образа, прагматического воздействия на рещипиента.

Метод. В статье применяется метод функиионального анализа дискурса.

Результаты. В результате определено, что целенаправленный подбор эффективных прагматических средств воздействия основан на коммуникативном замысле автора, применение речевых стратегий и тактик интенционально. Дискурс массмедиа является функиионально обусловленной системой смыслов, в которой пропозиции связаны между собой прагма-семантическими и логико-семантическими отнотениями.

Выводы. Сделан вывод о том, что знание механизмов речевого воздействия может помочь специалистам различных профессиональных сфер в повышении коммуникативной компетенции, и в цеелом способствует противостоянию речевым манипуляциям.

Ключевые слова: прагматика; функциональный анализ; дискурс массмедиа; риторика; экспрессивность; фразеологический глагол.

\section{PHRASAL VERBS AS A MEANS OF INCREASING THE EXPRESSIVITY OF MASS MEDIA DISCOURSE}

\section{Radyuk A.V., Khramchenko D.S.}

Purpose. The article is devoted to the study of phrasal verbs functioning as one of the speech means that makes up the system of speech 
expression of the communicative intention of the author of a publicistic article. The purpose of the article is to analyse the speech means used in the English-language quality press to form an evaluative color of events, a certain image, and produce a pragmatic impact on the recipient.

Methodology. The authors use the method of functional analysis of discourse. Results. As a result, it was determined that the targeted choice of effective pragmatic means of influence is based on the communicative intention of the author, the use of speech strategies and tactics is intentional. Mass media discourse is a functionally determined system of meanings in which propositions are linked by pragma-semantic and logical-semantic relations.

Conclusions. It is concluded that knowledge of the mechanisms of speech influence can help specialists in various professional spheres in improving their communicative competence, and contributes to the resistance to speech manipulations.

Keywords: pragmatics; functional analysis; mass media discourse; rhetoric; expressiveness; phrasal verb.

\section{Введение}

В статье анализируются дискурсивные характеристики современного дискурса массмедиа. Необходимость изучения прагма-семантических свойств речи обусловлена высоким экспрессивным потенциалом публицистики и тем фактом, что язык средств массовой информации все больше направлен на воздействие на читателя.

Актуальность исследования обусловлена значительным влиянием средств массовой информации на сознание и жизнедеятельность людей. Как показывает практика, современный дискурс, представленный в печатных и сетевых СМИ, находится в процессе постоянного развития, обнаруживая новые темы, через которые формируется имидж политиков, бизнесменов, глав государств, партий, и имидж отдельных стран. Все это в конечном счете определяет убеждения, мнения, оценки, которые воспринимаются аудиторией как правдивые, заслуживающие доверия, сомнительные или лживые. Способность корректно воспринимать печатную инфор- 
мацию на сегодняшний день является востребованным качеством различных специалистов. Необходимость интерпретировать и переосмысливать ее является неотъемлемой составляющей дискурса как коммуникативного события $[10 ; 17]$. От типа адресата также зависит, какие речевые средства будет выбирать автор речевого произведения для речевого воздействия, к каким ценностям будет апеллировать.

Целью статьи является выявление коммуникативно-прагматических особенностей дискурса массмедиа и роль фразеологических глаголов в повышении его экспрессивности. В связи с этим в исследовании решается ряд задач:

- проанализировать корпус примеров, содержащих фразеологические глаголы различных типов;

- идентифицировать функции дискурса массмедиа;

- описать прагматический потенциал фразеологических глаголов и их роль в функциональной организации дискурса.

Научная новизна статьи заключается в том, что впервые фразеологические глаголы рассматриваются как элемент динамически развивающейся прагма-семантической системы дискурса, восприятие дискурса анализируется в контексте экстралингвистических факторов и перцепции как нелинейного многовекторного процесса.

\section{Материалы и методы}

Работа проводилась в рамках функционально-прагматической парадигмы. Метод функционального анализа предполагает, что прагматический потенциал фразеологических глаголов определяется путем выявления коммуникативных целей автора речевого произведения, определения роли экстралингвистических параметров дискурса, анализа закономерностей отбора тех или иных речевых средств для определенной коммуникативной цели и их взаимовлияния.

Языковым материалом послужили образцы дискурса онлайн-изданий the Economist, the Financial Times, Quirks, Adage, the Guardian, ВВС за период февраль - ноябрь 2020 года. 


\section{Фразеологические глаголы в дискурсе СМИ}

Как отмечал А.В. Кунин, фразеологизмы обусловлены аналитическими свойствами английского языка и являются высокоинформативными единицами. Фразеологическая единица - это лексически неделимое, устойчивое по составу и структуре, целостное по значению словосочетание, воспроизводимое в виде готовой речевой единицы [4]. Фразеологические глаголы являются одной из разновидностей фразеологических единиц и представляют собой как идиомы (немотивированные словосочетания, семантически целостные, значение которых не равно сумме значений их составляющих), так и фразеологические единства (значение складывается из значений компонентов) [2].

Такие свойства делают фразеологизмы и фразеологические глаголы, в частности, удобным средством для экспрессивного описания явлений, широко распространенного в дискурсе массмедиа.

Медиадискурс - это публичная, целенаправленная и зафиксированная в печатной или электронной форме разновидность взаимодействия [18]. Дискурс СМИ находится в общественном когнитивном пространстве и имеет свойства неспонтанной речи. В зависимости от канала передачи сообщения, дискурс массмедиа ориентирован на читателей или слушателей. Он носит опосредованный характер и «транслируется» через носитель информации, как в устном, так и в письменном виде, при этом он адресован гипотетическому, воображаемому образу читателя, слушателя или зрителя.

Важно, что реципиент сообщения не может мгновенно ответить автору дискурса, то есть он является асинхронным. С развитием новых медиа-технологий появилась возможность комментировать статью / видеоролик и вступать в дискуссию с другими комментаторами по поводу содержания статьи. Это подчеркивает дискурсивные свойства современного пространства масс-медиа, в котором речь становится центром «коммуникативного события» [1].

Манипулятивная природа дискурса многократно подчеркивалась лингвистами, специалистами по риторике, журналистике, литературоведению. Как отмечает А. Партингтон, широко распространен се- 
годня феномен спин-докторинга (spin-doctoring), призванный адаптировать новостное сообщение и выставить его в выгодном свете [14]. Термином «спин» также обозначают профессиональную риторику. А. Партингтон указывает на существование речевых средств, направленных на противодействие речевому воздействию: "Persuading people to accept your version of events, of the truth, in competition with other versions, has been at the very dialogic heart of rhetoric since classical times. And just as Socrates was alert to the efforts of the doctors of sophistry $<\ldots>$, we have our modern defences against the doctors of spin." [14, p. 124] (Убеждение людей принять вашу версию событий, истину в соревновании с другими версиями было в диалогических основах риторики с классических времен. И так же как Сократ был внимателен к усилиям экспертов софистики, у нас есть современные способы защиты от пиар специалистов) (Перевод наш - А.Р.).

Таким образом, наряду с выявлением механизмов прагматического воздействия лингвистами осуществляется описание средств противостояния речевым и когнитивным манипуляциям.

В зависимости от обстоятельств речевая манипуляция в СМИ может реализовывать разнообразные речевые стратегии [11]. Так, имеет место классическое доказательство фактов; убеждение как комплекс взглядов, верований, доказательств; оспаривание противоположного мнения и призыв отказаться от собственной точки зрения; внушение, навязывание некой точки зрения при несформировавшемся взгляде на проблему [3].

Манипулятивный дискурс также является объектом изучения суггестивной лингвистики, связанной с психологическими и когнитивными процессами, отвлечением осознания.

\section{Функции дискурса массмедиа}

Важной особенностью языка СМИ является сочетание двух функций языка: риторической и информативной. Воспринимая публицистический текст, говорящий не только получает определенный объем информации, но и находится под влиянием системы риторических средств, составляющих прагматическое простран- 
ство дискурса. Публицистический стиль связан с эмоциональной вовлеченностью и оценкой, не свойственный другим стилям, будь то научный или официальный. Для него характерен специфический вокабуляр, включающий единицы с социально-обусловленным компонентом оценки.

Оценочность могут выражать тактики положительной и отрицательной оценки и соответствующие им речевые средства - метафоры, окказионализмы, авторские неологизмы [16]. Зачастую в переносном смысле употребляются:

1) научные термины: атмосфера (the atmosphere of confidence), положительный (positive result);

2) концепты сферы искусства: дуэт (the duet of liberals and conservatives), шоу (political show);

3) военная терминология: фронт (war front), авангард (the advance guard of the avant-garde);

4) спортивная терминология: раунд (last round) и др.

Отличительным свойством дискурса массмедиа является насыщенность эмоционально окрашенной лексикой из сферы экономически, политики, бизнеса, торговли, информационных технологий:

1) мелиоративные слова (положительная коннотация): sustainable, charity, prosperity, welfare, grow, progress,

2) пейоративные слова (отрицательная коннотация): recession, devaluation, sabotage, jeopardise, rival, apartheid.

\section{Повышение экспрессивности через создание образности}

Как известно, дискурс воспринимается читателем нелинейно. На процесс восприятия влияют такие внешние факторы, как ассоциации, авторитетность издания, знания и опыт адресата в данной области, источник и носитель информации, и многие другие.

В следующем отрывке идет речь о модернизации компании Ниссан.

Turning down the volume. Nissan's newish boss wants to re-engineer the troubled carmaker. [13]

Анализируя заголовок, читательская аудитория сталкивается с многозначностью выражения turn down the volume. В составе устой- 
чивого словосочетания находим лексему volume, который в сочетании с фразеологическим глаголом turn down чаще всего понимается как «снизить громкость». При ознакомлении с содержанием статьи адресату становится понятно, что в компании Ниссан планируются перестановки, которые приведут к сокращению сотрудников. Таким образом, первоначальное восприятие заголовка интерпретируется иначе: «сокращение размера компании». Полное содержание статьи, контекст, выводимый из реалий функционирования компании, позволяет добиться правильной трактовки заголовка. Игра со смыслами, эффект обманутого ожидания вовлекают читателя в посторенние совместного с автором когнитивно-дискурсивного пространства дискурса.

В научном сообществе ведется дискуссия о характере речевого воздействия - его интенциональной или произвольной природе [5; 6; 8; 9]. Необходимо отметить, что такие приемы, как формулирование заголовков, отличаются запланированностью и целенаправленным применением. Какого эффекта удается достигнуть благодаря вышеуказанным риторическим фигурам? Во-первых, читатель вовлекается в осмысление содержания дискурса. Важен не столько информационный посыл, сколько его интерпретация, совместные размышления адресата и адресанта. Дискурс реализуется как процесс, коммуникативное событие. Во-вторых, повышается прагматическая эффективность высказывания. Применение более утонченных формулировок, косвенных средств выражения обладает более высоким перлокутивным эффектом, нежели прямолинейное сообщение о реорганизации Ниссан. В-третьих, работает принцип экономии речевых средств, при этом не наносится ущерб плану содержания. Наоборот, в сжатой форме автору удается объединить широкую палитру пропозиций и логических связей:

а) компания столкнулась с трудностями;

б) у компании новый руководитель;

в) руководитель проводит реформы;

г) реформы посредством оптимизации.

Анализируя данный отрывок методом функционального анализа, обнаруживаем, что пропозиции связаны между собой прагма-се- 
мантическими и логико-семантическими отношениями (подробнее о видах отношений [15]), объединяющими их в одну функционально обусловленную систему смыслов:

а - б (исключение - переключение);

б - в (включение - спецификация);

в - г (включение - расширение).

Эти отношения обеспечивают динами эволюции смысловой системы.

В следующем отрывке фразовые глаголы используются для повышения образности дискурса.

Until 2017 Nissan was racing ahead. That year it sold $5.8 \mathrm{~m}$ vehicles and raked in an operating profit of $\$ 5.2 \mathrm{bn} .<\ldots>$ Nissan fell short of targets in America, one of its biggest markets [13].

Коммуникативная цель отрывка - противопоставить прежнее и нынешнее экономическое состояние автоконцерна. Описывая процесс развития компании, автор прибегает к метафоре динамики движения автомобиля. Позитивный этап описывается с помощью фразеологического глагола racing ahead. Он ассоциирует прогресс компании со стремительным движением гоночной машины. Доходы компании характеризуются фразеологическим глаголом rake in, в сознании читающего ассоциирующимся с огромными объемами, зачастую получаемыми нечестно (букв. rake in - загребать). Таким образом, данные речевые средства реализуют речевую тактику противопоставления в масштабах речевой стратегии усиления воздействия.

Употребление речевых стратегий и тактик в печатной прессе интенционально. Так, в статье о реформах в Индонезии коммуникативной целью является создание отрицательного образа переизбранного индонезийского президента.

The two men are, of course, one: President Joko Widodo, or Jokowi, who came to power in 2014 and was reelected last year. On the face of things, the new "omnibus" law, which takes a saw to regulations around employment, among other things, is a sensible effort to make it easier to do business and thus promote investment. The economy is indeed tied up 
in red tape. $<\ldots>$ What is the government doing to help the unemployed to retrain, or to keep tiny businesses afloat? [7]

Фразеологический глагол to take a saw to употреблен в значении «положить конец законам в области трудоустройства» и является частью паремии «рубить сук, на котором сидишь». Отрицательная коннотация, связанная с этой поговоркой, переносится на оценку реформ в индонезийской экономике. Таким образом, тактика скрытого параллелизма является неявным инструментом занижения имиджа политика.

Фразеологический глагол to be tied up (in red tape) также характеризует положение вещей как бедственное. Прагматический потенциал данного глагола заключается в создании образа бездействия и беспомощности.

Фразеологический глагол to keep afloat использован в значении «удержать на плаву» (крошечные компании), что в качестве характеристики задач нового правительства является уничижительным.

Тактика дискредитации представлена и другими речевыми средствами. В совокупности негативная окраска фразеологических глаголов наряду с отрицательно окрашенными лексемами weaken, discourage, steepest collapse, tiny businesses, идиомой red tape, усиливает образ чиновника как неэффективного, а его действий как вредных и незаконных.

\section{Выводы}

Как показал анализ, фразеологические глаголы используются в дискурсе массмедиа довольно часто и наиболее востребованной их функцией является создание образности описываемых явлений. Английский дискурс СМИ является областью, в которой весьма ярко прослеживается экспрессивный потенциал фразеологических глаголов. Необходимость убеждать, демонстрировать авторитетное мнение, формировать повестку дня в различных общественных сферах делает язык публицистики инструментом риторического воздействия. Как любой целенаправленный вид деятельности, дискурс СМИ оказывает прагматический эффект с целью достижения 
коммуникативной цели. Для этого адресант выстраивает риторику комплексно, от общей цели к частным задачам и выбору конкретных речевых средств. Построение такой прагма-семантической системы позволяет реципиенту воспринимать дискурс нелинейно, делает его «объемным», и, следовательно, более убедительным. Ввиду этого представляется необходимым дальнейшее исследование спектра средств создания и интерпретации убеждающего дискурса.

\section{Список литературы}

1. Дейк Т.А. ван. К определению дискурса. [Электронный ресурс]. URL: http://psyberlink.flogiston.ru/internet/bits/vandijk2.htm (дата обращения: 28.11.2020).

2. Дмитриева О.П. Фразовый глагол как часть фразеологической системы английского языка // Филологические науки. Вопросы теории и практики. 2016. № 8-1(62). С. 106-109.

3. Стернин И.А. Введение в речевое воздействие. Воронеж: «Истоки», 2001. 266 c.

4. Фразеологическая единица. [Электронный ресурс]. URL: www. textologia.ru/slovari/lingvisticheskie-terminy/frazeologicheskayaedinica/?q=486\&n=2015 (дата обращения 26.11.2020)

5. Dynel M. Intention to deceive, bald-faced lies, and deceptive implicature: Insights into Lying at the semantics-pragmatics interface // Intercultural Pragmatics. 2015. Vol. 12(3). Pp. 332-309 .

6. Haugh M. Intention in pragmatics // Intercultural Pragmatics. 2008. Vol. 5(2.) Pp. 99-110.

7. How not to reform Indonesia// The Economist. 2020, October, 15. [Электронный ресурc]. URL: https://www.economist.com/ asia/2020/10/15/how-not-to-reform-indonesia (дата обращения: 20.10.2020)

8. Kecskes I. Pragmatics and its interfaces as related to the expression of intention // Introduction. Pragmatics \& Cognition. 2019. Vol. 26(1). Pp. 1-4.

9. Khramchenko D. Humour in English discourse of mass media: functional-linguistic analysis \& teaching // 11th international conference of 
education, research and innovation (ICERI2018). 2018. Seville, Spain. Pp. 8934-8938.

10. Kurtz H. Spin Cycle: How the White House and the Media Manipulate the News. New York: Touchstone, 1998. 368 p.

11. Malyuga E.N. Functional approach to professional discourse exploration in linguistics. Singapore, 2020. 335 p.

12. Malyuga E.N., Tomalin B. Communicative strategies and tactics of speech manipulation in intercultural business discourse // Training, Language and Culture. 2017. Vol. 1(1). Pp. 28-45.

13. Nissan's newish boss wants to re-engineer the troubled carmaker // The Economist. 2020, July, 2. [Электронный pecypc]. URL: https://www. economist.com/business/2020/07/02/nissans-newish-boss-wants-to-reengineer-the-troubled-carmaker (дата обращения: 20.11.2020).

14. Partington A. Rhetoric, bluster and on-line gaffes. The tough life of a spin-doctor // New Media Language / Edited by Jean Aitchison and Diana M. Lewis. London, New York: Routledge, 2004. Pp. 116-126.

15. Ponomarenko E.V. Discourse functional relations revisited: mastering causativity as means of communicative impact // 9th international conference on education and new learning technologies (Edulearn17). 2017. Pp. 4706-4712.

16. Radyuk A.V. Discursive strategies in conflict communicative situations of English economic discourse // Вопросы прикладной лингвистики. 2015. №17. C. 118-129.

17. Weingart P., Engels A., Pansegrau P. Risks of communication: discourses on climate change in science, politics, and the mass media // Public understanding of science. 2000. Vol. 9(3). Pp. 261-283. DOI: 10.1088/0963-6625/9/3/304

18. Zhai Y., Yan J., Zhang H., Lu W. Tracing the evolution of AI: conceptualization of artificial intelligence in mass media discourse // Information discovery and delivery. 2020. Vol. 48(3). Pp. 137-149. DOI: 10.1108/ IDD-01-2020-0007

\section{References}

1. Dijk T.A., van. Kopredeleniyu diskursa [Towards the definition of discourse]. URL: http://psyberlink.flogiston.ru/internet/bits/vandijk2.htm 
2. Dmitrieva O.P. Frazovyy glagol kak chast' frazeologicheskoy sistemy angliyskogo yazyka [Phrasal verb as part of the phraseological system of the English language]. Filologicheskie nauki. Voprosy teorii i praktiki, 2016, no 8-1 (62). P. 106-109.

3. Sternin I.A. Introduction to speech impact [Vvedenie v rechevoe vozdeystvie].Voronezh: Istoki, 2001. 266 p.

4. Frazeologicheskaya edinitsa [Phraseological unit]. URL: www.textologia.ru/slovari/lingvisticheskie-terminy/frazeologicheskaya-edini$\mathrm{ca} / \mathrm{q}=486 \& \mathrm{n}=2015$

5. Dynel M. Intention to deceive, bald-faced lies, and deceptive implicature: Insights into Lying at the semantics-pragmatics interface. Intercultural Pragmatics, 2015 , vol. 12, №3. P. 309-332.

6. Haugh M. Intention in pragmatics. Intercultural Pragmatics, 2008, vol. 5, №2. P. 110-99.

7. How not to reform Indonesia. The Economist, 2020, October, 15. URL: https://www.economist.com/asia/2020/10/15/how-not-to-reform-indonesia

8. Kecskes I. Pragmatics and its interfaces as related to the expression of intention. Introduction. Pragmatics \& Cognition, 2019, vol. 26, №1. P. 1-4.

9. Khramchenko D. Humour in English discourse of mass media: functional-linguistic analysis \& teaching. 11th international conference of education, research and innovation (ICERI2018). Seville, Spain. 2018. P. 8934-8938.

10. Kurtz H. Spin Cycle: How the White House and the Media Manipulate the News. New York: Touchstone, 1998. 368 p.

11. Malyuga E.N. Functional approach to professional discourse exploration in linguistics. Singapore, 2020. 335 p.

12. Malyuga E.N., Tomalin B. Communicative strategies and tactics of speech manipulation in intercultural business discourse. Training, Language and Culture, 2017, vol. 1, №1. P. 28-45.

13. Nissan's newish boss wants to re-engineer the troubled carmaker. The Economist, 2020, July, 2. URL: https://www.economist.com/business/2020/07/02/nissans-newish-boss-wants-to-re-engineer-the-troubled-carmaker 
14. Partington A. Rhetoric, bluster and on-line gaffes. The tough life of a spin-doctor. New Media Language. Edited by Jean Aitchison and Diana M. Lewis. London, New York: Routledge. 2004. P. 116-126.

15. Ponomarenko E.V. Discourse functional relations revisited: mastering causativity as means of communicative impact. 9th international conference on education and new learning technologies (Edulearn17). 2017. P. 4706-4712.

16. Radyuk A.V. Discursive strategies in conflict communicative situations of English economic discourse. Issues of applied linguistics, 2015, №17. P. 118-129.

17. Weingart P., Engels A., Pansegrau P. Risks of communication: discourses on climate change in science, politics, and the mass media. Public understanding of science, 2000, vol. 9, №3. P. 261-283. DOI: 10.1088/0963$6625 / 9 / 3 / 304$

18. Zhai Y., Yan J., Zhang H., Lu W. Tracing the evolution of AI: conceptualization of artificial intelligence in mass media discourse. Information discovery and delivery, 2020, vol. 48, №3. P. 137-149. DOI: 10.1108/ IDD-01-2020-0007

\section{ДАННЫЕ ОБ АВТОРАХ}

Радюк Александра Владимировна, кандидат филологических наук, доцент

Российский университет дружбы народов

ул. Миклухо-Маклая, 6, г. Москва, 117198, Российская Федеращчия

radyuk-av@rudn.ru

Храмченко Дмитрий Сергеевич, доктор филологических наук, профессор

Московский государственный институт международных отношений (университет) МИД Российской Федераиии пр. Вернадского, 76, г. Москва, 119454, Российская Федерачия d.s.khramchenko@icloud.com 


\section{DATA ABOUT THE AUTHORS}

Radyuk Alexandra Vladimirovna, Candidate of Philology, Associate Professor

Peoples' Friendship University of Russia

6, Miklukho-Maklaya Str., Moscow, 117198, Russian Federation radyuk-av@rudn.ru

SPIN-code: 5339-2336

ORCID: 0000-0002-2818-0619

ResearcherID: D-6689-2015

Khramchenko Dmitry Sergeevich, Doctor of Philology, Professor

Moscow State Institute of International Relations (University) at the Ministry of Foreign Affairs of the Russian Federation 76, Vernadsky prospect, Moscow, 119454, Russian Federation d.s.khramchenko@icloud.com SPIN-code: 1579-6336 OCID: 0000-0003-3038-8459 ResearcherID: N-8008-2018 